\title{
A SOCIALIZAÇÃO PROFISSIONAL DO TREINADOR ESPORTIVO COMO UM PROCESSO FORMATIVO DE AQUISIÇÃO DE SABERES
}

\author{
PROFESSIONAL SOCIALIZATION OF THE SPORT COACH AS A FORMATIVE \\ PROCESS OF KNOWLEDGE ACQUIRING
}

\section{LA SOCIALIZACIÓN PROFESIONAL DEL ENTRENADOR DEPORTIVO COMO UN PROCESO DE FORMACIÓN EN LA ADQUISICIÓN DE CONOCIMIENTOS}

\author{
Heitor de Andrade Rodrigues*, Roberto Rodrigues Paes**, \\ Samuel de Souza Neto***
}

\section{Palavras-chave}

Socialização.

Conhecimento.

Treinadores.

\begin{abstract}
Resumo: 0 objetivo da pesquisa foi investigar o processo de socialização profissional de treinadores de basquetebol de jovens atletas, buscando identificar os saberes apreendidos ao longo do tempo e analisar a natureza dos processos formativos por trás da apropriação desses saberes. Optou-se por uma pesquisa do tipo qualitativa, sendo a entrevista narrativa, na perspectiva etnossociológica, a técnica para coleta de dados. Os sujeitos participantes foram 13 treinadores. Os resultados revelaram a apropriação de um conjunto diversificado de saberes (experienciais, acadêmicos e profissionais), fruto de socializações sucessivas sustentadas pela educação artesanal, formação acadêmico-científica e prática reflexiva.
\end{abstract}

Keywords

Socialization

Knowledge.

Coaches

Palabras clave

Socialización.

Conocimiento

Entrenadores.
Abstract: The purpose of the research was to investigate the process of professional socialization of youth basketball coaches, in order to identify the knowledge acquired throughout time and analyze the nature of the formation processes behind the appropriation of knowledge. It was chosen a quantitative research, with the narrative interview, ethno-sociological perspective, to collect technical data. Thirteen coaches were chosen for the research. The results revealed the appropriation of a diverse set of knowledge (experiential, academic and professional), the product of successive socialization, supported by artisanal education, academic-scientific background and reflective practice.

Resumen: El objetivo de esta investigación es el proceso de socialización profesional de los entrenadores de jóvenes en el baloncesto, buscando identificar los conocimientos adquiridos a través del tiempo y analizar la naturaleza de los procesos de formación que llevan a la apropiación del conocimiento. Optamos por la investigación cualitativa, para la recogida de datos se utilizaron la entrevista narrativa, en la perspectiva etnossociológica. Los sujetos fueron 13 entrenadores. Los resultados revelaron la apropiación de un conjunto diverso de conocimiento (experiencial, académico y profesional), fruto de sucesivas socializaciónes, con el apoyo de la educación artesanal, formación académicocientífico y la práctica reflexiva.
* Universidade Federal de Goiás (UFG). Goiânia, GO, Brasil.

E-mail: triheitor@yahoo.com.br

** Universidade Estadual de Campinas (UNICAMP). Campinas, SP, Brasil. E-mail: robertopaes@fef.unicamp.br

*** Universidade Estadual Paulista (UNESP). Rio Claro, SP, Brasil. E-mail: samuelsn@rc.unesp.br

Recebido em: 05-05-2015 Aprovado em: 14-09-2015

(c) (1) (8) Licence 


\section{INTRODUÇÃO}

Este estudo discorre sobre a socialização do treinador esportivo como um processo de profissionalização e produção de saberes, tendo como recorte o basquetebol.

Embora, no espaço social do esporte, o treinador seja um elemento-chave na formação de jovens atletas e equipes adultas (BOSSCHER et al., 2009), essa questão tem suscitado diferentes desafios e ações.

No que se refere aos desafios, merece destaque o movimento internacional da International Council for Coaching Excellence ${ }^{1}$, tendo em vista a profissionalização dos treinadores. As ações, para fazer frente a esses desafios, têm sido evidenciadas pela criação de programas nacionais de formação e certificação de treinadores ${ }^{2}$ e 0 incentivo à produção e publicação de pesquisas científicas sobre os treinadores (MALLET et al., 2009, TRUDEL; GILBERT; WERTHNER, 2010).

No âmbito da pesquisa científica internacional, registra-se 0 aumento na quantidade de publicações (GILBERT; TRUDEL, 2004) e, mais recentemente, a diversificação dos referenciais teóricos e metodológicos que sustentam as pesquisas sobre os treinadores (TRUDEL; CULVER; GILBERT, 2014). Portanto, ganham relevo as pesquisas sobre os contextos de aprendizagem da profissão de treinador (TRUDEL; GILBERT, 2006), revelando que eles aprendem a profissão por meio de fontes diversificadas de conhecimento. Nelson, Cushion e Potrac (2006) reconhecem essa diversidade, sugerindo uma classificação baseada em três contextos de aprendizagem: formal, não formal e informal.

A aprendizagem no contexto formal ocorre em espaços educacionais institucionalizados, dispondo de currículos padronizados, pois a formação culmina na certificação dos participantes (cursos de Educação Física). A aprendizagem no contexto não formal é identificada por um engajamento voluntário em atividades organizadas de forma sistemática, em curto período de tempo, direcionadas a temáticas específicas em conferências e clínicas. A aprendizagem no contexto informal ocorre fora dos limites das instituições de ensino em processo de aquisição e acúmulo de conhecimento, habilidade, valores e atitudes, por meio de experiências informais ao longo da vida, um tipo de aprendizagem autoguiada, por meio, por exemplo, de internet, leitura de manuais de treinamento, livros e artigos científicos, observação de vídeos etc. (NELSON; CUSHION; POTRAC, 2006).

Na realidade brasileira, a formação inicial de treinadores fica a cargo dos cursos de Educação Física ou de Ciências do Esporte. Por sua vez, a formação continuada tem sido evidenciada nas confederações esportivas e, mais recentemente, no Comitê Olímpico Brasileiro (COB). Em 2012, o COB, por meio do Instituto Olímpico Brasileiro, criou a Academia Brasileira de Treinadores com o objetivo de complementar a formação profissional de treinadores. No caso específico do basquetebol, o reconhecimento da necessidade de formação pode ser constatado com a criação, em 2009, da Escola Nacional de Treinadores de Basquetebol (ENTB). Apesar desse incremento, no Brasil, há pouca informação disponível sobre a efetividade desses cursos na formação e prática dos treinadores (MILISTETD, 2015).

1 Disponível em: <www.icce.ws $>$. Acesso em: 4 fev. 2015

2 Exemplos: National Coaching Certification Program (Canadá), National Coach Accreditation Scheme, Australian Institutes and Academies (Austrália), United Kingdom Coaching Certificate (Reino Unido), National Standards for Sport Coaches e o National Council for the Accreditation of Coach Education (EUA). 
No que diz respeito à pesquisa científica, o número de publicações sobre os treinadores tem aumentado, mas ainda é reduzido. Essa situação pode ser confirmada pela ausência de uma agenda de pesquisa sobre a formação e o desenvolvimento profissional, na qual se sobressaem pesquisas isoladas ou de pequenos grupos. Dentre os objetos/temas insuficientemente explorados destaca-se o número reduzido de estudos que buscam investigar as competências e os saberes dos treinadores (BALBINO, 2005, EGERLAND, 2009, RAMOS, 2008). De acordo com Freidson (1996), delimitar um corpo de conhecimentos e habilidades especializadas é uma iniciativa das ocupações que visam controlar seu trabalho. Freire, Verenguer e Reis (2002) destacam que a definição do saber profissional é um dos elementos imprescindíveis na constituição da identidade profissional e no reconhecimento social da categoria profissional.

A formalização do conjunto de conhecimentos e saberes que sustentam a prática dos profissionais é um dos pilares da profissionalização e condição essencial a qualquer profissão, pois o reconhecimento social perpassa a investigação e a demarcação dos saberes necessários ao desenvolvimento das tarefas profissionais.

Nas profissões que envolvem dimensões relacionais (TARDIF, 2000), as perspectivas sociais se tornam preponderantes na trajetória pessoal e profissional de um indivíduo no desenvolvimento profissional, o que implica conhecer como que se deu a sua socialização profissional.

Desse modo, o recorte escolhido nos desafia a olhar para a prática como um lugar de formação e um espaço social em que a socialização se manifesta na forma de saberes, práticas e cultura (GAUTHIER et al., 1998), pois a aprendizagem da ocupação de treinador, em sua socialização, segue um itinerário que envolve contextos de vida, interações sociais e práticas pedagógicas.

Neste contexto, a socialização profissional pode ser compreendida como a aprendizagem dos valores, crenças e formas de concepção do mundo próprios de uma determinada cultura ocupacional, podendo ser identificada como a aquisição de um ethos profissional, não necessariamente expresso em palavras, que dá ao agente em socialização o sentido do jogo (FREITAS, 2002).

As ações, crenças e valores estão enraizados na primeira socialização, contexto familiar, mas não estão reduzidas nelas mesmas, pois a pessoa tem contato com outras pessoas ao longo de toda vida, caracterizando a socialização secundária como "[...] qualquer processo subsequente que introduz um indivíduo já socializado em novos setores do mundo objetivo de sua sociedade" (BERGER; LUCKMANN, 2009, p. 169).

Em função desses aspectos, esta pesquisa tem como objetivo investigar o processo de socialização profissional de treinadores de basquetebol de jovens atletas, buscando identificar os saberes apreendidos ao longo do tempo e analisar a natureza dos processos formativos por trás da apropriação desses saberes. Escolheu-se pesquisar os treinadores de basquetebol que tratam da formação de atletas, por esta ser um processo que envolve as etapas iniciais e que é responsável pela ascensão nas categorias superiores, podendo dar indicativos para uma melhor organização do esporte nacional.

\section{PROCEDIMENTOS METODOLÓGICOS}

Optou-se pela pesquisa qualitativa, estudo descritivo, por ser uma abordagem que estuda os fenômenos em seus cenários naturais e busca interpretá-los tomando por base 
os significados que as pessoas Ihes conferem (DENZIN; LINCOLN, 2006), tendo na técnica da narrativa de vida, na perspectiva etnossociológica, o caminho escolhido. Bertaux (2010) assinala que a narrativa de vida consiste em uma produção discursiva na qual o participante é convidado a relatar um episódio de sua experiência vivida, delimitar os personagens que participaram, descrever suas relações, explicar suas razões de agir, descrever os contextos de ação e fazer os julgamentos sobre os personagens, suas ações e os contextos de ocorrência.

A perspectiva etnossociológica se circunscreve a episódios específicos que estão delimitados pelo objeto de estudo e pela escolha dos próprios sujeitos da pesquisa. Dessa forma, a narrativa de vida consiste em experiências filtradas, orientadas e predeterminadas pelo pesquisador (BERTAUX, 2010).

Esta investigação foi aprovada junto ao Comitê de Ética em Pesquisa (CAAE - no 11226312.0.0000.5404) e, posteriormente, desenvolvida com o consentimento dos treinadores.

Para a seleção dos treinadores participantes, identificou-se um conjunto de cidades do estado de São Paulo que se têm destacado como centros de formação de jovens atletas nas categorias de formação feminina e masculina, quais sejam: Americana, Osasco, Franca, Limeira, Campinas e São Paulo. Após a seleção das cidades, recorreu-se ao cadastro da Federação Paulista de Basquetebol, o qual fornece nome, vínculo institucional e os anos nos quais os treinadores estiveram vinculados à instituição, o que permitiu selecionar um grupo de treinadores que se enquadrasse nos seguintes critérios: experiências de trabalho em categorias de formação/ base, com participação em competições federadas em nível estadual, nacional ou internacional.

Participaram 13 treinadores de basquetebol (T1 a T13), os quais foram selecionados por sua expertise (competência reconhecida pelos pares) e disponibilidade em participar. As idades dos treinadores oscilaram de 23 anos a 48 anos, três eram do sexo feminino e dez do sexo masculino. O menos experiente estava há dois anos na ocupação, enquanto que o mais experiente estava há 23 anos como treinador. Desse grupo, cinco treinadores eram diplomados em licenciatura e bacharelado e oito em licenciatura plena. A maioria (12) em instituições particulares de ensino. Em relação à formação continuada, todos relataram ter participado de pelos menos uma clínica de formação de treinadores; seis já participaram de cursos da Escola Nacional de Treinadores (ENTB) e cinco realizaram especialização (lato sensu) em áreas correlatas à Educação Física.

Neste contexto, a entrevista narrativa se desenvolveu em um roteiro menos estruturado de questões, no qual o pesquisador estimula e encoraja o sujeito a contar a história de um acontecimento importante de sua vida e contexto social, pois a ideia básica é reconstruir acontecimentos pela perspectiva do sujeito (BAUER; GASKELL, 2008). Para o desenvolvimento da entrevista optou-se pela definição de uma questão geradora: - Como você se tornou treinador de basquetebol? Além disso, elencou-se um conjunto de temas norteadores (relação com o esporte e Educação Física Escolar, os primeiros contatos com o basquetebol, os professores e treinadores, o curso de Educação Física, o exercício profissional) que pudessem orientar o pesquisador durante a entrevista. As entrevistas foram realizadas individualmente, com duração média de 55 minutos, sendo todas elas registradas com o auxílio de gravador digital.

No que diz respeito à análise dos dados, Bertaux (2010) alerta que as narrativas de vida não liberam de uma só vez todos os seus segredos e desse modo a análise minuciosa dos dados obtidos constitui uma fase imprescindível da pesquisa, fundamental para descrever e interpretar os relatos colhidos. Assim, o autor sugere quatro fases: 
(1) Transcrição das entrevistas, no intuito de traduzir as palavras e os elementos de comunicação não verbal em um formato textual;

(2) Reconstrução da estrutura diacrônica/temporal das narrativas e reconstituição dos grupos de coabitação presentes nas narrativas, procedimentos relevantes na identificação da origem social dos saberes dos treinadores, bem como os contextos e instituições em que esses saberes foram socializados;

(3) Análise compreensiva, no intuito de explicitar as informações e significações presentes nas narrativas, fazendo emergir indícios preliminares sobre fenômenos propriamente sociais e;

(4) Análise comparativa, com o intuito de cotejar as recorrências identificadas nas narrativas e, com isso, construir hipóteses plausíveis sobre o objeto de estudo.

\section{RESULTADOS E DISCUSSÃO}

A partir da análise das narrativas de vida dos treinadores de basquetebol constatamos que a apropriação dos saberes é um processo que ocorre ao longo da vida, fruto das inúmeras socializações vivenciadas pelos indivíduos nos mais diversos contextos (família, escola, treinamento, universidade, ao longo da carreira profissional).

Os dados revelaram que, para além da formação obtida no curso de Educação Física, os saberes dos treinadores pesquisados foram adquiridos em diferentes fases da vida. Identificou-se que as socializações sucessivas, experimentadas pelos treinadores ao longo da vida pessoal e profissional, foram constituindo um reservatório de saberes, em permanente transformação, que foi mobilizado em resposta às demandas de trabalho.

Esse resultado referenda o que tem sido divulgado na literatura (CUSHION; ARMOUR; JONES, 2003, MALLET et al., 2009, NELSON; CUSHION; POTRAC, 2006), de que os treinadores de esporte aprenderam o oficio por meio de fontes diversificadas de conhecimento no contexto formal, não formal e/ou informal, podendo-se destacar três períodos: socialização pré-profissional - experiências anteriores à universidade; socialização profissional - formação inicial e socialização profissional ao longo da carreira -; as experiências de trabalho.

\subsection{Socialização pré-profissional - experiências anteriores à universidade}

Esse período representa a construção dos primeiros laços afetivos com o basquetebol, o fascínio pela modalidade, o desejo de jogar, assistir a jogos e fazer parte do mundo do basquetebol. Os mediadores desse primeiro contato foram os professores das escolinhas de esporte nos clubes e prefeituras e os antigos treinadores. Além de constituir um momento fundamental na formação esportiva, enquanto praticante ou atleta, esse período foi essencial no processo de formação profissional dos treinadores, sustentado por experiências de aprendizagem informal e pouco sistematizadas, o que denominamos de aprendizagem profissional por meio da imersão na cultura esportiva.

A aprendizagem por imersão na cultura esportiva vai ao encontro das reflexões de Trudel e Gilbert (2006) sobre a aprendizagem experiencial ou metáfora da participação, na qual o treinador aprende pela convivência e observação dos contextos esportivos vivenciados ao longo de sua história de vida, seja na função de jogador, de espectador, entre outras formas de engajamento voluntário no esporte. No caso dos treinadores destacam-se as aprendizagens 
obtidas nos ambientes de iniciação e treinamento do basquetebol, convivendo, ouvindo e ajudando os antigos professores e treinadores, entre outros atores significativos no âmbito do sistema esportivo, tais como os colegas, adversários, árbitros etc.

[...] como eu morava próximo à quadra, eu gostava muito de estar lá, ver outras equipes treinando, ajudar outras equipes, eu gostava muito de estar na quadra e ela (a antiga treinadora) me usava até como ajudante, vem cá você vai me ajudar a dar os treinos, vai lá pegar as bolas, então eu ficava até como assistente dela $[\ldots](T 13$, grifo nosso).

Um processo formativo caracterizado por uma espécie de educação artesanal, processo tradicional de formação, no qual o aprendiz é iniciado e conduzido no ofício por um mestre artesão com reconhecida competência. Sobre as características da educação artesanal, Cunha (2000, p. 2) descreve:

[...] desenvolve-se mediante processos não sistemáticos, a partir do trabalho de um jovem aprendiz com um mestre de ofício, em sua própria oficina, com seus próprios instrumentos e até mesmo morando em sua casa. Ajudando-o em pequenas tarefas, que lhes são atribuídas de acordo com a lógica da produção, 0 aprendiz vai dominando, aos poucos, o ofício.

Ramos (2009), referindo-se a esse processo a partir do termo "escola de ofício", indica que essa experiência e aprendizagem são sustentadas pela transmissão de um "saber fazer" que passa de pai para filho, do artesão para o aprendiz, do mestre para o discípulo.

As experiências no campo esportivo viabilizaram uma série de oportunidades de aprendizagem de saberes da cultura do basquetebol e da cultural profissional dos treinadores. Sobressaíram os conhecimentos específicos sobre o basquetebol, aqueles que identificam a modalidade, suas técnicas, táticas, regras e metodologias de ensino do jogo.

Na literatura internacional (ABRAHAM et al., 2006, GILBERT; CÔTÉ, 2013) esses conhecimentos têm sido referenciados como uma dimensão substantiva do conhecimento profissional do treinador. Para Abraham et al. (2006) o conhecimento profissional é a junção dos conhecimentos específicos do esporte (técnicas, táticas e regras) com os conhecimentos das ciências do esporte (fisiologia, biomecânica, psicologia, teoria do treinamento etc.) e o conhecimento pedagógico.

Ainda em relação aos treinadores pesquisados, destaca-se um conjunto de valores sobre a iniciação esportiva e o treinamento no basquetebol. Na iniciação esportiva prevaleceram valores como ludicidade, divertimento, prazer e prática desinteressada. Já no período do treinamento prevaleceram valores como esforço, disciplina, comprometimento, responsabilidade, vitória, derrota, seleção, rendimento, entre outros valores que modificam a postura dos antigos treinadores se comparada às dos professores da iniciação.

A socialização pré-profissional constitui-se como um contexto privilegiado de aprendizagem profissional do basquetebol, sustentada pelos pressupostos da educação artesanal, que contribuiu para a apropriação de saberes relacionados à dimensão do "saber fazer", principalmente os elementos técnico-táticos do basquetebol, e do "saber ser" relacionados às concepções sobre a iniciação e o treinamento no basquetebol, os quais viabilizaram a integração dos treinadores ao mundo do basquetebol e, mais tarde, foram, em grande parte, resgatados na prática profissional. 


\subsection{Socialização profissional - formação inicial}

Os treinadores avaliaram a contribuição do curso de Educação Física na formação para ser treinador, destacando os conhecimentos e saberes socializados ao longo do curso. Os participantes foram unânimes em afirmar que houve aproveitamento na esfera da iniciação esportiva, mas no campo do treinamento deixou a desejar. Para o trabalho com equipes em nível de treinamento, o curso foi considerado insuficiente.

[...] eu acho que o curso da faculdade, pro treinamento, pro treinamento é muito pouco, é pouca informação, a gente usa bastante coisa da fisiologia, da teoria do treinamento. [...] Ajudou, me ajudou bastante, só que eu acho que ainda é muito pouco pra alguém que quer ser um treinador de basquete. [...]. Na minha própria faculdade não tem como eu chegar e falar: "Pô, eu quero ser um treinador de basquete" (T1).

Apesar de reconhecerem os limites do curso de Educação Física na formação para se tornar treinador, os participantes reconheceram o papel do curso na socialização de alguns saberes incorporados à atuação profissional. Surpreendentemente, a área de conhecimento com maior incidência nas narrativas dos treinadores $(n=8)$ foi a Didática, a qual esteve atrelada à Pedagogia, o que Abraham et al. (2006) denominam o conhecimento pedagógico do treinador.

Eu penso que a Faculdade de Educação Física, ela somou muito em termos de Didática, em termos de uma certa noção de Pedagogia, mesmo quando você não estava falando de basquete, estava na aula de voleibol, mas via o professor ensinar a sequência pedagógica. Você já tinha um discernimento que precisava existir [...] (T8).

[...] na situação de Didática, a faculdade me ajudou muito a lidar com as crianças. Eu fiz estágio em escola, e isso me ajudava no planejamento de aula, como lidar com as crianças. Acho que a faculdade é muito bacana nessa parte de orientar 0 professor para lidar com a criança, lidar com a pessoa (T6).

Os relatos valorizaram os conhecimentos relativos à organização do ensino, do planejamento, das estratégias metodológicas, do relacionamento com os alunos, e estes são, apesar de atrelados a uma pedagogia, reconhecidamente objetos da Didática.

A discussão sobre a importância da Didática no relato dos treinadores confirma que o processo de ensino está profundamente enraizado no processo de treinamento. A suspeita é de que as atividades de ensino e treinamento estejam permanentemente entrelaçadas nas categorias menores, já que a formação do atleta é um processo que ocorre em longo prazo, pela progressão em diversas fases e cada fase exige a aprendizagem de novos conhecimentos que devem ser necessariamente ensinados e posteriormente treinados.

Os treinadores destacaram ainda os conhecimentos veiculados em disciplinas específicas do currículo, tais como Fisiologia, Anatomia, Teoria do Treinamento e Psicologia, 0 que Abraham et al. (2006) denominam os conhecimentos das ciências do esporte.

[...] você tem uma base de Fisiologia, porque eu não sabia nada de Fisiologia; você tem uma base de Anatomia que vai te ajudar no basquete, eu não sabia nada de Anatomia. Você tem uma base de, de treinamento esportivo, que eu não sabia absolutamente nada, não sabia o que era uma adaptação, como era feito a adaptação do esporte e tudo mais. Você ter uma noção de Psicologia que ajuda muito o treinador (T1, grifo nosso). 
Mais nas outras áreas, a parte de teoria das outras áreas, como, por exemplo, metodologia, área de Fisiologia, área de Psicologia, essas áreas assim contribuíram bastante; foi coisa que eu me interessei mais também para desenvolver (T13, grifo nosso).

A partir dos dados revelados pode-se concluir que o curso de Educação Física contribuiu para a socialização de saberes que podem ser agrupados em três áreas centrais. A primeira, com maior de incidência, foi a Didática, acompanhada pela Pedagogia. Identificaram-se, entre os treinadores, inquietações relativas ao planejamento e à organização do treino, à gestão do grupo de atletas durante o treino e, principalmente, à escolha de estratégia metodológica capaz de envolver os atletas no treino.

A segunda área, com menor incidência, compreende os conhecimentos de natureza biológica, conhecimentos do corpo humano e, principalmente, do metabolismo energético e periodização do treinamento físico, tais como os veiculados nas disciplinas de Fisiologia, Anatomia e Teoria do Treinamento, que são os conhecimentos que respondem às demandas da preparação física.

A terceira área, também com menor incidência, compreende os conhecimentos da Psicologia, desde aqueles que permitem compreender o desenvolvimento das crianças e adolescentes, mas principalmente aquelas habilidades de relacionamento que qualificam o treinador para intervir em situações de conflito, identificar as emoções vivenciadas pelos atletas, dialogar, convencer, apoiar, motivar.

Esses resultados revelaram que o curso de Educação Física parece colaborar significativamente com a formação dos treinadores, ao menos nos campos da Didática, Psicologia, Fisiologia, Anatomia e Teoria do Treinamento.

No entanto, não podemos desconsiderar que na relação dos treinadores com o curso de Educação Física houve conflitos. $O$ treinador T6 afirmou: "[...] só que na prática eu acho que facilita muito mais. Sou muito mais da prática do que da teoria. Eu acho que a gente tem que ter a teoria, mas só vai lapidar isso na prática, esse que eu acho que é o caminho (T6, grifo nosso)". Já o treinador T7 fez crítica ao que ele definiu como profissional teórico.

[...] vejo cada pessoa dando aula em tudo quanto é lugar de basquete. Você já fez o moleque correr? Você já se envolveu numa competição? O que é necessário, né, pra você vincular a prática com a teoria? Você não sabe, você só é teórico. Você pode ser o melhor teórico do mundo, eu não te respeito, eu não te respeito (T7, grifo nosso).

No relato dos treinadores (T6 e T7), transpareceu certo preconceito em relação à teoria, sobretudo aquela produzida no contexto universitário. Essa aversão ao conhecimento produzido na universidade pareceu ser consequência do modelo de formação adotado nos cursos de Educação Física.

Como destacado por Pérez Gómez (1995), o modelo de formação sustentado pela racionalidade técnica contribui para a divisão do trabalho entre os profissionais reconhecidos como da prática (treinadores) e aqueles da teoria (professores/pesquisadores da universidade), com relativa autonomia de ambos, o que na realidade gera um processo de subordinação dos níveis mais próximos da prática aos mais abstratos de produção de conhecimento, provocando isolamento e embates corporativistas. 
Desse modo, apesar de identificada a contribuição do curso de Educação Física na constituição dos saberes dos treinadores pesquisados, não podemos desconsiderar que as características do processo formativo (racionalidade técnica) têm contribuído para a degradação do estatuto profissional do treinador, na medida em que não reconhece a relevância dos saberes produzidos na experiência profissional e, por vezes, desqualifica a contribuição da prática na formação.

Por outro lado, o fato dos treinadores terem reconhecido a importância dos conhecimentos e saberes relativos à Didática, Fisiologia, Anatomia, Teoria do Treinamento e Psicologia permite inferir que o curso foi capaz de "abrir os olhos" dos treinadores para algumas demandas e saberes da atuação profissional, sobre os quais ainda não haviam se atentado.

\subsection{Socialização profissional ao longo da carreira - as experiências de trabalho}

Este período compreendeu a entrada no mundo do trabalho, sendo possível acessar as experiências e impressões dos treinadores sobre o exercício da profissão. A inquirição sobre esse período foi no intuito de compreender o papel das experiências profissionais na constituição dos saberes, mais especificamente, do conjunto de saberes considerados fundamentais para a atuação profissional.

O conhecimento valorizado foi aquele relativo ao conteúdo específico da modalidade, onze participantes afirmaram que o treinador tem de conhecer os fundamentos, técnicas, táticas e regras do basquetebol.

Eu acho que ele precisa saber do jogo, precisa entender como é um jogo de basquete, precisa gostar muito, precisa assistir muito basquete, porque o basquete mudou muito [...]. [...] os fundamentos, é óbvio que precisa saber, quais são os fundamentos, a regra do campeonato para saber passar. Mas eu acho assim, tem que entender como funciona um jogo de basquete, o que está acontecendo no mundo em relação ao basquete [...]. [...] gostar do basquete, assistir o basquete, estar por dentro do que está acontecendo, as nomenclaturas [...] (T6, grifo nosso).

O segundo grupo de saberes, lembrado por nove treinadores, incluiu os conhecimentos e habilidades relativos à Psicologia. Para identificar estes saberes, os treinadores utilizaram expressões como: "é preciso saber lidar com as pessoas", "lidar com os atletas". O termo "lidar" expressa a necessidade de ter conhecimentos e, sobretudo, habilidades para motivar os atletas, liderar a equipe, identificar a personalidade do atleta, agir em momentos críticos do treino e da competição, estabelecer e incentivar bons relacionamentos interpessoais, o que Gilbert e Côté (2013) classificam como o conhecimento interpessoal do treinador.

Essa parte também de lidar com o atleta. Acho que é a parte principal, lidar com o atleta, você motivar sempre, tudo. A parte técnica pega muito para trabalhar alto nível, mas nas categorias de base saber lidar com o atleta, você ter a confiança do atleta, você faz ele render o dobro do que ele poderia render (T1, grifo nosso).

[...] o primordial é saber lidar com pessoas também. Eu trabalhei com uns dez times diferentes aqui, diferentes faixas etárias, diferentes períodos da vida deles e cada período eles estão de um jeito diferente, seja criança, pré-adolescente, adolescente, quase adulto [...] lidar com vaidades, com ego. Eu acho que trabalhar com basquete é muito mais que ir ali dar um treino e ir embora para casa. É lidar muito com pessoas, saber tirar o melhor de cada um, não fazer ele desanimar ou achar que é muito bom (T6, grifo nosso). 
No terceiro grupo de saberes, destacado por cinco treinadores, estão os conhecimentos de Fisiologia do Exercício e de Teoria do Treinamento. Os treinadores não chegaram a aprofundar a importância desses saberes, mas destacaram que, quando não é possível contar com o trabalho de um preparador físico, é necessário ter conhecimentos sobre 0 funcionamento do corpo dos atletas, os metabolismos predominantes no basquetebol e noções sobre periodização do treinamento físico.

O quarto grupo de saberes, valorizado por quatro treinadores, foi aquele relacionado ao campo da Didática. Os treinadores afirmaram que não basta saber o conteúdo específico da modalidade, é preciso saber ensinar. Defenderam ainda a importância do planejamento, destacando que o treinador precisa saber organizar e sistematizar seus conteúdos de treino.

É válido relembrar que, na discussão sobre o papel do curso de Educação Física na constituição dos saberes dos treinadores, a Didática emergiu na socialização profissional ao longo da carreira, e foi o conhecimento do jogo que assumiu uma posição de destaque.

Essa constatação parece indicar que o terreno profissional exerce um papel preponderante sobre a aprendizagem dos conhecimentos específicos da modalidade, uma vez que no âmbito da socialização pré-profissional esses saberes já tinham sido evidenciados. $E$ que o curso de Educação Física se constitui como espaço privilegiado de aprendizagem dos conhecimentos relativos à Didática, entre outros saberes valorizados pelos treinadores.

Outro ponto a ser ressaltado é que os saberes indicados pelos treinadores como fundamentais para enfrentar as demandas do trabalho guardam relações com um conjunto de desafios da profissão elencados pelos próprios treinadores. Dentre eles, merecem destaque os desafios impostos ao ensino do basquetebol (planejar e organizar o treino, ensinar o jogo) e ao relacionamento com os atletas (compreender as novas gerações, motivar, apoiar, lidar com os pais). Esses resultados parecem justificar a mudança na ordem de importância dos saberes, quando os treinadores foram confrontados com a realidade de trabalho.

A articulação entre os desafios da profissão e os saberes necessários à atuação do treinador permite classificá-los na perspectiva do que Tardif (2000) define como saberes profissionais. Os saberes mobilizados em resposta às demandas do trabalho, que estão a serviço da resolução de problemas concretos e que, portanto, são saberes da ação, saberes do trabalho, saberes no trabalho. Esses saberes articulam-se ao que Gilbert e Côté (2013) denominam de conhecimento intrapessoal do treinador, que se refere ao conhecimento de si mesmo, às habilidades de introspecção e, principalmente, à capacidade reflexiva sobre os dilemas do próprio trabalho.

Sobre a importância e especificidade dos saberes profissionais, Tardif $(2000$, p. 11) destaca:

Essa hipótese é forte, na medida em que não diz somente que os saberes profissionais se referem ao trabalho, como uma teoria se refere a um objeto ou uma prática, mas vai mais longe, dizendo que os saberes profissionais são saberes trabalhados, saberes laborados, incorporados no processo [...], que têm sentido em relação às situações de trabalho e que é nessas situações que são construídos, modelados e utilizados de maneira significativa pelos trabalhadores.

Pode-se afirmar que os saberes profissionais dos treinadores são construídos em estreita relação com os problemas, as dificuldades e os desafios colocados pela prática profissional no campo do treinamento. 
As características desse processo formativo parecem apontar para um tipo de aprendizagem profissional ancorada na prática reflexiva, nos termos do que Schön (2000) define como o prático-reflexivo, já que, ao se depararem com os desafios do trabalho, os treinadores avaliam retrospectivamente seus saberes e passam a produzir saberes em estreita relação com as demandas do contexto de treinamento.

Gilbert e Trudel (2001), em pesquisa com seis treinadores de jovens esportistas, investigaram como esses profissionais aprendem com a experiência. Pautados nos estudos de Schön (2000), Gilbert e Trudel (2001) afirmam que a reflexão é responsável pela mediação entre a experiência e o conhecimento, e o crescimento profissional é acompanhado pela reflexão na ação e pela reflexão sobre a ação. Esses são mecanismos referenciados como uma conversa reflexiva desencadeada pelos dilemas do treinamento.

Os treinadores investigados por Gilbert e Trudel (2001) desenvolveram e refinaram suas estratégias de treinamento por meio da prática reflexiva, o que indica que os treinadores não são meros técnicos que aplicam irrefletidamente os conhecimentos de base científica produzidos no ambiente acadêmico. Ao contrário, por meio do processo reflexivo, os treinadores produzem conhecimento útil ao treinamento, o que permite solucionar os problemas que emergem da prática cotidiana.

\section{CONSIDERAÇÕES FINAIS}

Os dados revelaram que os treinadores constituíram seus saberes ao longo da vida, fruto do investimento pessoal e das interações com os diversos sujeitos e instituições que cruzaram a vida de cada treinador.

No âmbito da socialização pré-profissional, a aprendizagem dos saberes foi social e espaço-temporal, ocorrendo pela imersão na cultura esportiva, denominada de educação artesanal, na perspectiva das "escolas de ofício" em que o aprendiz aprende com o mestre de ofício, sendo introduzido nos segredos do ofício. Sobressaiu um conjunto de saberes experienciais expressos nos conhecimentos específicos sobre o basquetebol, suas técnicas, táticas, regras e metodologias de ensino, bem como um conjunto de valores sobre a iniciação esportiva e o treinamento.

Em relação ao curso de Educação Física, observamos que a aprendizagem dos saberes acadêmico-científicos foi cognitiva, plural e heterogênea com ênfase para Didática, Fisiologia, Anatomia, Teoria do Treinamento e Psicologia. Embora este processo tenha sido sustentado pelos pressupostos da racionalidade técnica na lógica disciplinar, os objetivos a serem atingidos pelos treinadores são diferentes, não dando margem para uma unidade teórica de conteúdo, mas para uma coerência pragmática em relação à prática. Em função disso surgem os questionamentos relacionados à produção e transmissão de conhecimentos científicos para serem aplicados aos problemas colocados pela prática.

No âmbito da carreira ficou evidenciada a emergência de um conjunto de saberes profissionais (saberes da ação), no qual se observou que esta aprendizagem é relacional, personalizada e situada, trazendo subjacente a ela um capital cultural. Destacam-se os conhecimentos sobre o jogo e o ensino do jogo, conhecimentos e habilidades para se relacionar com os atletas e, com menor incidência, os conhecimentos de Fisiologia, Teoria do Treinamento e Didática. 
Em relação às características do processo formativo, há indícios de que os saberes profissionais foram produzidos a partir de uma prática reflexiva dos treinadores (reflexão na ação, reflexão sobre a ação e reflexão retrospectiva sobre a ação) em estreita relação com os desafios colocados pela prática profissional.

Do ponto de vista do desenvolvimento profissional, observamos indícios de uma ocupação que oscila entre um ofício e uma profissão, pois de um lado se encontram vestígios de uma educação artesanal e, de outro, a influência dos conhecimentos universitários, na perspectiva de uma formação universitária de alto nível, fora do contexto de trabalho.

Cabe ressaltar que, no bojo do movimento de profissionalização dos treinadores, considerando a relevância expressa na definição de um corpo especializado de saberes e conhecimentos científicos necessários à formação e ao exercício profissional, a pesquisa confirma a urgência em considerar o terreno profissional como um elemento indispensável na definição dos saberes profissionais dos treinadores, o que ratifica a premência de tentar definilos a partir de uma epistemologia da prática profissional.

\section{REFERÊNCIAS}

ABRAHAM, Andy; COLLINS, Dave; MARTINDALE, Russell. The coaching schematic: validation through expert coach consensus. Journal of Sports Science, London, v. 24, n. 6, p. 549-564, 2006.

BALBINO, Hermes Ferreira. Pedagogia do treinamento: método, procedimentos pedagógicos e as múltiplas competências do técnico nos jogos desportivos coletivos. 2005. $92 \mathrm{f}$. Tese (Doutorado em Educação Física) - Faculdade de Educação Física, Universidade Estadual de Campinas, Campinas, 2005.

BAUER, Martin; GASKELL, George. Pesquisa qualitativa com texto, imagem e som: um manual prático. 7. ed. Petrópolis: Vozes, 2008.

BERGER, Peter; LUCKMANN, Thomas. A construção social da realidade. São Paulo: Vozes, 1998. BERTAUX, Daniel. Narrativas de vida: a pesquisa e seus métodos. Natal: EDUFRN, 2010.

BOSSCHER, Veerle De et al. Explaining international sporting success: an international comparison of elite sport systems and policies in six countries. Sport Management Review, Auckland, n. 12, p. 113136, 2009.

CUNHA, Luiz Antônio. 0 ensino de ofícios artesanais e manufatureiros no Brasil escravocrata. São Paulo: UNESP, 2000.

CUSHION, Christopher; ARMOUR, Kathy; JONES, Robyn. Coach education and continuing professional development: experience and learning to coach. Quest, Illinois, v. 55, n. 3, p. 215-230, 2003.

DENZIN, Norman; LINCOLN, Yvonna. Introdução: a disciplina e a prática da pesquisa qualitativa. In: DENZIN, Norman; LINCOLN, Yvonna (Org.). 0 planejamento da pesquisa qualitativa: teorias e abordagens. 2. ed. Porto Alegre: Artmed, 2006. p. 15-42.

EGERLAND, Ema Maria. Competências profissionais de treinadores esportivos. 2009. $44 \mathrm{f}$. Dissertação (Mestrado em Educação Física) - Centro de Desportos, Universidade Federal de Santa Catarina, Florianópolis, 2009.

FREIDSON, Eliot. Para uma análise comparada das profissões: a institucionalização do discurso e do conhecimento formais. Revista Brasileira de Ciências Sociais, São Paulo, n. 11, p. 141-154, 1996. 
FREIRE, Elisabete dos Santos; VERENGUER, Rita de Cássia Garcia; REIS, Marise Cisneiros da Costa. Educação Física: pensando a profissão e a preparação profissional. Revista Mackenzie de Educação Física e Esporte, São Paulo, v. 1, n. 1, p. 39-46, 2002.

FREITAS, Maria Nivalda de Carvalho. Organização escolar e socialização profissional de professores iniciantes. Cadernos de Pesquisa, n. 115, p. 155-172, 2002.

GAUTHIER, Clermont et al. Por uma teoria da pedagogia: pesquisas contemporâneas sobre o saber docente. ljuí: Unijuí, 1998.

GILBERT, Wade; TRUDEL, Pierre. Analysis of coaching science research published from 1970-2001. Research Quarterly for Exercise and Sport, Washington v. 75, n. 4, p. 388-399, 2004.

GILBERT, Wade; TRUDEL, Pierre. Learning to coach through experience: reflection in Model Youth Sport Coaches. Journal of Teaching in Physical Education, Champaign, v. 21, p. 16-34, 2001.

GILBERT, Wade; CÔTÉ, Jean. Defining coaching effectiveness: a focus on coaches' knowledge. In: POTRAC, Paul; GILBERT, Wade; DENISON, Jim. Routledge handbook of sports coaching. London: Routledge, 2013. p. 147-159.

MALLET, Clifford et al. Formal vs informal coach education. International Journal of Sports Science and Coaching, Brentwood, v. 4, n. 3, p. 325-334, 2009.

MILISTETD, Michel. A aprendizagem profissional de treinadores esportivos: análise das estratégias de formação inicial em Educação Física. 2015. 70f. Tese (Doutorado em Educação Física) - Centro de Desportos, Universidade Federal de Santa Catarina, Florianópolis, 2015.

NELSON, Lee; CUSHION, Christopher; POTRAC, Paul. Formal, nonformal and informal coach learning: a holistic conceptualization. International Journal of Sports Science and Coaching, Brentwood, v. 1, n. 3, p. 247-259, 2006.

PÉREZ GÓMEZ, Ángel Ignacio. O pensamento prático do professor - a formação do professor como profissional reflexivo. In: NÓVOA, Antonio. Os professores e sua formação. 2. ed. Lisboa: Dom Quixote, 1995. p. 102-154.

RAMOS, Glauco Nunes Souto N. S. Escolas de ofício, profissão educação física e sociedade. Motriz, Rio Claro, v. 15, n. 4, p. 919-924, 2009.

RAMOS, Valmor. 0 treino do basquetebol na formação jovens desportivas: estudo do conhecimento pedagógico de treinadores. 2008. 115 f. Tese (Doutorado em Ciência do Desporto) Faculdade de Desporto, Universidade do Porto, Porto, 2008.

SCHÖN, Donald Alan. Educando o profissional reflexivo: um novo design para o ensino e a aprendizagem. Porto Alegre: Artes Médicas Sul, 2000.

TARDIF, Maurice. Saberes profissionais dos professores e conhecimentos universitários: elementos para uma epistemologia da prática profissional dos professores e suas consequências em relação à formação para o magistério. Revista Brasileira de Educação, Rio de Janeiro, n. 13, p. 5-13, jan./abr. 2000.

TRUDEL, Pierre; CULVER, Diane; GILBERT, Wade. Publishing coaching research. In: NELSON, Lee; GROOM, Ryan; POTRAC, Paul. Research Methods in Sports Coaching. London: Routledge, 2014. p. 250-260.

TRUDEL, Pierre; GILBERT, Wade. Coaching and coach education. In: KIRK, David; MACDONALD, Doune; O'SULLIVAN, Mary. Handbook of physical education. London: Sage, 2006. p. 516-539.

TRUDEL, Pierre; GILBERT, Wade; WERTHNER, Penny. Coach education effectiveness. In: LYLE, John; CUSHION, Christopher. (Org.). Sports coaching: professionalisation and practice. London: Elsevier, 2010. p. 135-152. 